\title{
sciendo
}

\section{Statistical analysis of living conditions and quality of life in Romania}

\author{
Mihaela CAZACU \\ The Bucharest University of Economic Studies, Bucharest Romania \\ czc.mihaela@gmail.com \\ Emilia ȚIȚAN \\ The Bucharest University of Economic Studies, Bucharest, Romania \\ emilia.titan@csie.ase.ro
}

\begin{abstract}
The way how people define their standards, perceptions and values influence the quality of their lives. The quality of life is a social trend, an important link of the statistical system in any country, and for its measurement all general statistical methods are used: from systematization and data grouping to the calculation of parameters. This article's aim is to address how the quality of life is perceived in Romania and the relationships between the main indicators that generally define human development.
\end{abstract}

Key words: quality of life, living standard, quantitative analysis

\section{Introduction}

The concept of quality of life has been analyzed and developed in high performing societies, more specifically in North American society. Basically, it started from the notion that any economic growth should not be an end in itself but first of all it must be a way to create better living conditions to meet the needs of the peoples.

In the current context, quality of life is a challenge because we are in a period of unpredictable and rapid changes and people's values are changing in this very dynamic society. Thus, if in the past the quality of life was assimilated to the idea of abundance and the satisfaction of material needs, the quality of life also includes the quality of the environment, quality of living conditions, health, education and training in the current society mindset. Living conditions are a reference to the standard of living, being a quantitative indicator. The concept of living conditions can be replaced by its synonym, living standards, and represents the degree of development of an economy that has made it possible to meet material needs at a higher level than the population of other states.

The real meaning of life is the relationship between what we do, the clear results of our work, and, on the other hand, what we have intended to be and to achieve. If life, at one stage, thanks to successful actions, falls from the point of view of value in ideal protection, we can say that it realizes meaning and is lived with satisfaction.

Romania was one of the first socialist countries to adopt these concepts immediately after the 1970s. 20 years later, in 1990, the Institute for Research on Quality of Life was set up with the purpose of conducting research in the field of quality of life in the context of transformations political, economic and social policies after 1989, developing methodologies 
for assessing the quality of life. Quality of life is one of the important links of the statistical system in any country.

The Dutch, some of the happiest people on the planet, describe this state of well-being through the popular "hygge", and this word has its roots in the words hygee (resteless), tryghed (safety) and trivsel (goodness). Thus, hygge is only the product of a particular special ethos, developed in Denmark at the end of the nineteenth century and early twentieth century. During this period, the interstellar of the society turned to relaxation, authenticity, scientific rationality and the comfort of home and home life.

The standard of living is the set of economic, non-economic, social, cultural and political conditions that society creates for its members, but also the ability and ability of individuals to better meet their income needs. Definitive aspects of living standards are related to: level and evolution of income; the level and evolution of the prices of goods and services constituting the consumption of the population; the level and structure of consumption of goods and services; working conditions and leisure; living conditions; health status and access to insurance services; education and access to culture and art, etc.

The novelty of the paper consists in the development of quantitative analysis based on advanced techniques for statistical and econometric data analysis on quality of life topic. The approach of my previous papers for this topic was to have a general overview about the definition of quality of life and wellbeing, status of quality of life as global level and now this paper is focused exactly what is happening in Romania.

\section{Literature Review}

As a general assessment in this field it can be said that in Romania the level of quality of life is modest, this claim being supported by indicators of living conditions starting with the macroeconomic indicators of results to microeconomic indicators at household level or even at individual level.

The most important research on the quality of life in Romania is the Diagnosis of Quality of Life. Estimates of the evolution of quality of life indicators are made using the 54 indicators, indicators that during the 1990-1999, 2003, 2006 and 2010 surveys had fluctuations: some increased more, some less, crisis-sensitive indicators and public policy. The purpose of this paper is to have a clearer picture of how the population of Romania relates to different components of the quality of life, from the essential areas such as living conditions, education, health, employment, family, social environment, the political environment, the community conditions, the mood of the population in general and, last but not least, the means of spending leisure time.

The most critical elements of the quality of life are tax fears and rising prices in general, insufficient incomes or low accessibility of jobs. Measures taken or desirable to be taken in the future to reduce the quality of life deterioration include: increasing GDP in GDP, investing in education and research, reorganizing public sector employees, avoiding capping and homogenization of wages in the public domain. Considering the answers to the question: Of the following, please tell me what is most important in order to have a good life nowadays? in Eurobarometer 67.1 (2007) it is noted that the most important percentage of about $62 \%$ is to have a better job, implicitly income. 
What is a good life for romanians? (\%)

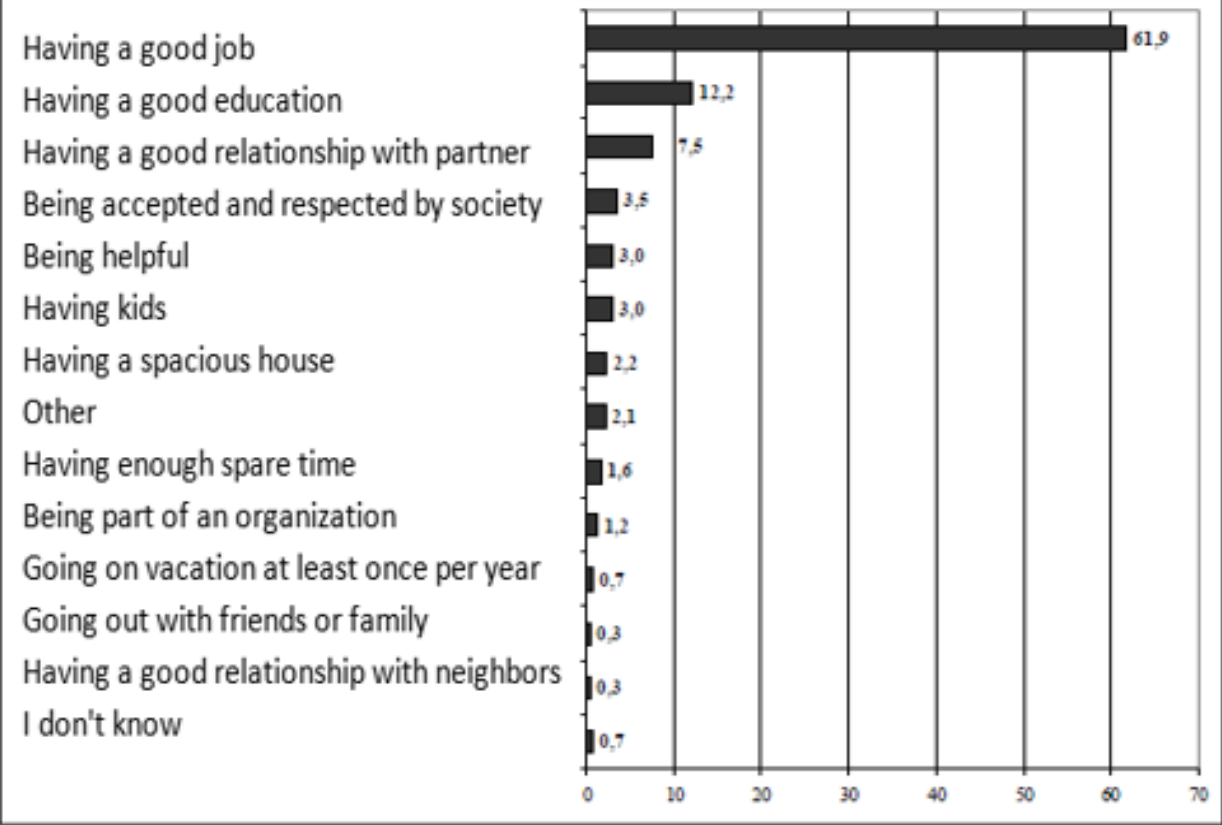

Source: Eurobarometru 67.1, 2007

Q: Which aspects are important in order to have a good life? (just one answer)

Figure 1. Results of the study related to quality of life for romanians Source: Eurobarometru 67.1, 2007

The most important conclusion we can draw from the results of these researches is that income in Romania is a fundamental resource for a high quality of life, this being the least appreciated element. Research shows that two-thirds of the population appreciate that incomes are not enough for the necessary, or just for the strict necessity.

In the European context, considering the answers received in TNS Opinion \& Social 2007, a better job remains the most important aspect of a desired life, but in most countries the situation changes for developed countries where the relationship with the partner becomes the most important aspect of a quality life. Assuming the existence of a job is closely related to the financial aspect of life, we can conclude that as the level of poverty decreases, the importance attached to the service for a better life decreases, and the importance of other aspects of family life is diminishing. In the current context, well-being is a mix of several elements among which the three most important are economic, investment and sustainability elements.

\section{Methodology}

There are two ways of assessing the quality of life: objective judgment and subjective appreciation.

\section{Objective approach}

It is based on statistical indicators provided by state institutions and non-governmental organizations; these indicators provide a global overall assessment of the quality of life. It addresses the quality of life at society level, taken as a whole. 
The living standard has an objective character, because it can only be achieved in certain parameters. As the science and technology evolved, the parameters taken into consideration (the natural environment, the social environment, education, health, political, economic, etc.) have undergone a series of changes, giving them the concept of living standards in this sense social-historical character. The living standard can be assessed on the basis of two distinct elements:

- The state of human life as it is at one point;

- The existence of a set of criteria (values) in relation to whom the state of life is rated as good or less good.

\section{Subjective appreciation}

It tries to identify the most important elements in the determination of individual's standard of living. These measurements are much more personal since they are based on individuals' assessments of the quality of their lives. Subjective appreciation goes down to individual or collectivities with a specific (geographic, cultural, living standard).

The quality of life can be measured by taking into account a number of dimensions of life including: family and friends, service, neighbors, community, health and education and the spiritual. The way these dimensions of life are perceived is strongly marked by three aspects: demographic characteristics, socio-economic conditions and cultural specificity. The appreciation of the quality of life is often subjective, because each assigns greater or less importance to a certain evaluation criterion depending on each person's needs and aspirations. Although the list of evaluation criteria is universal, the specific configuration of each criterion is different.

Analytically, the quality of life can be defined as the set of economic, social, cultural, political, etc. conditions in which people live, the content and nature of their activities, the characteristics of the relationships and processes involved, the goods and services to which they have access, adopted patterns of consumption, lifestyle, assessment of the extent to which circumstances and outcomes meet the expectations of the population, subjective states of satisfaction or dissatisfaction, etc.

One of the basic components of the quality of life is the concept of human development, introduced by the United Nations Development Program (UNDP). Through this concept, there is a clear need to place people, their needs and aspirations at the heart of any development effort. Economic policies must be primarily directed toward the individual.

Human development implies providing the way by which people can enjoy a healthy life; people must be able to participate actively in making those decisions that affect their lives, policies that take into account human development can allow individuals to acquire certain capacities that make them feel less vulnerable in everyday life. People must be the final beneficiaries of development. This new approach to development-by putting the individual at the center of attention-has forced economic development to be no longer an end in itself, but it has to be a means in the service of the people.

The most important areas of quality of life are: the economic situation, housing and the local environment, the education and credibility of the education system resulting from the employment rate after completing the studies, the relationship with the family members and the life partner, the balance between work and family life , health, subjective well-being, how to perceive the community to which the individual belongs, and society in general. 


\section{Advanced techniques for statistical and econometric data analysis}

In order to analyze the level of the quality of life in Romania, we considered the most important indicators in the field of human development: life expectancy at birth, birth rate, mortality rate, infant mortality rate, GDP per capita, unemployment rate, primary, the corruption perception index and, last but not least, an indicator describing the health of the environment to provide a wider context to the analysis. The data sources are multiple, they can be consulted in the bibliography and the indicators were analyzed in the period 20002012, 2012 being the year for which the information was complete for all the indicators considered.

The first indicator being analyzed is life expectancy at birth. It expresses the average number of years an individual may live in maintaining a constant mortality rate in the future regardless of the individual's gender. Life expectancy is also a measure of the quality of life in a country, and summarizes mortality for all ages, and may be a very important indicator for investing in human capital being needed for actuarial calculations.

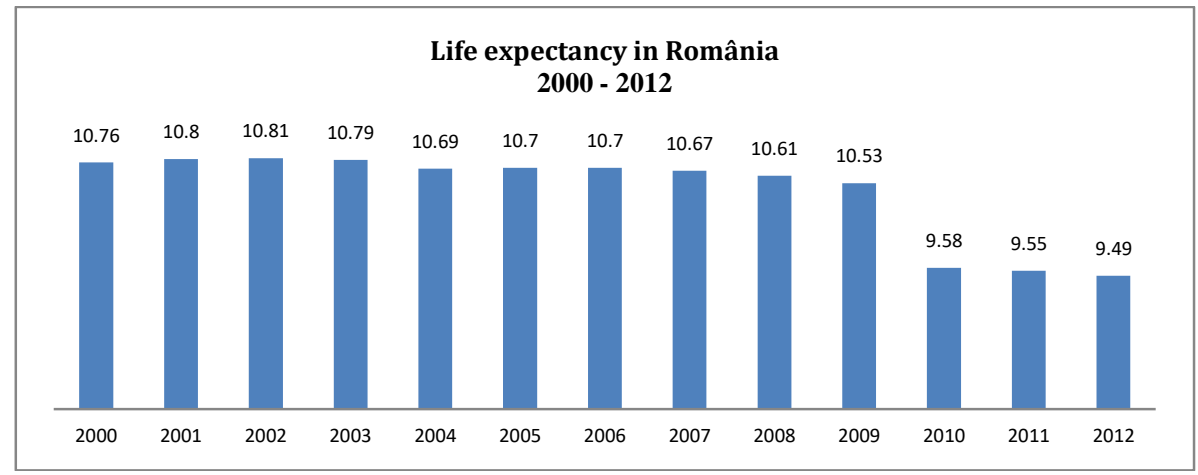

Figure 2. Life expectancy in Romania between 2000-2012

Source: Romania National Institute of Statistics

There is an increase in life expectancy in Romania, which means that living conditions have improved considerably over the past 10 years and can also be a proof of progress in medicine.

\begin{tabular}{|l|l|}
\hline \multicolumn{2}{|c|}{ Life expectancy } \\
\hline Mean & 71.8 \\
\hline Standard Error & 0.40 \\
\hline Median & 71.63 \\
\hline Skewness & 0.47 \\
\hline Range & 0.47 \\
\hline Minimum & 69.93 \\
\hline Maximum & 74.22 \\
\hline Sum & 933.68 \\
\hline Count & 13 \\
\hline
\end{tabular}

Figure 3. Descriptive statistics

Source: Authors' own research

According to the descriptive statistics, it can be noticed that in the period 2000- 2012 the average life expectancy was 71,8 years, over $50 \%$ of individuals having a life expectancy 
of over 71,6 years. The minimum value is 69,9 years reached in 2000 . The average coefficient of homogeneity is 2.01 , less than $30 \%$, indicating that the average is significant and the homogeneous population. Also, the values of the Skewness and Kurtosis coefficients indicate that the distribution is platictic and tilted to the left having several extreme values to the right.

The next indicator considered in the analysis is the birth rate. Natality is a demographic phenomenon being the asset of the natural balance. Birth rate is calculated as the ratio of the number of live births to the total population, therefore the birth rate is directly influenced by age and gender structure of the population.

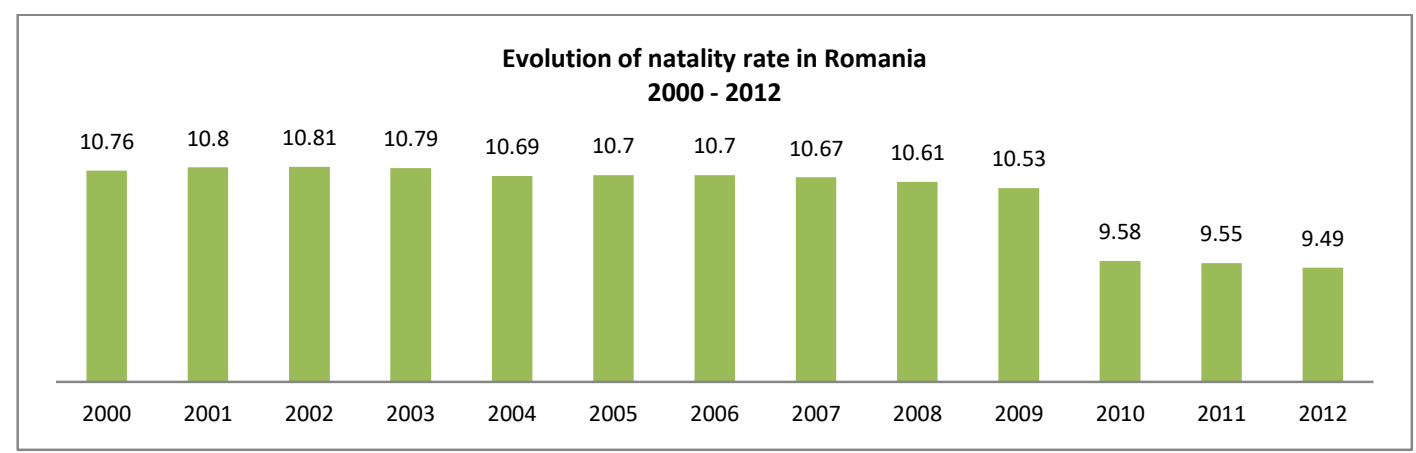

Figure 4. The evolution of natality rate in Romania

Source: Romania National Institute of Statistics

There has been a slight downward trend since 2006, which is worrying, but somewhat normal and due to the aging effect of the population.

\begin{tabular}{|l|l|}
\hline \multicolumn{2}{|c|}{ Natality Rate } \\
\hline Mean & 10.43 \\
\hline Standard Error & 0.1435 \\
\hline Median & 10.69 \\
\hline Skewness & -1.3698 \\
\hline Range & 1.32 \\
\hline Minimum & 9.49 \\
\hline Maximum & 10.81 \\
\hline Sum & 135.68 \\
\hline Count & 13 \\
\hline
\end{tabular}

Figure 5. Descriptive statistics

Source: Authors' own research

The average birth rate is $10.4 \%$, and in over $50 \%$ the birth rate exceeded the $10.6 \%$ threshold. Coefficient values showing the shape of the distribution indicate that the distribution is tilted to the right with small left values, emphasizing the fact that the natality rate is decreasing. Also, the positive value of the Kurtosis coefficient shows that the distribution is leptocurtic, sharper than a normal distribution with many values around the mean. In close association with birth rate, the opposite phenomenon that balances the natural balance is mortality. For this we analyzed the mortality rate and the infant mortality rate. 


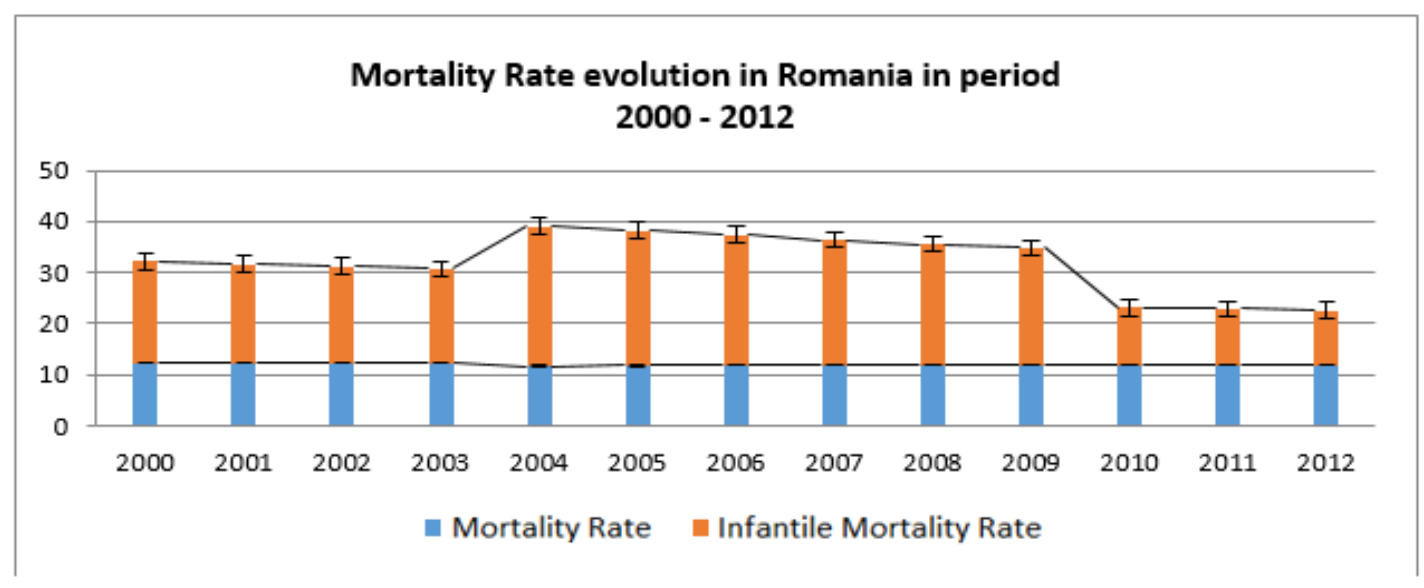

Figure 6. Mortality rate evolution in Romania

Source: Romania National Institute of Statistics

According to studies conducted at European level, Romania is one of the countries with the lowest life expectancy and at the same time the highest mortality rate. Between 2000 and 2012 there is a very high increase in the infant mortality rate, followed by a stabilization period.

\begin{tabular}{|l|r|l|r|}
\hline \multicolumn{2}{|c|}{ Mortality Rate } & \multicolumn{2}{c|}{ Infantile Mortality Rate } \\
\hline Mean & 11.94230769 & Mean & 19.99615 \\
\hline Standard Error & 0.064917639 & Standard Error & 1.628395 \\
\hline Median & 11.84 & Median & 19.84 \\
\hline Mode & 11.81 & Mode & \\
\hline Standard Deviation & 0.234063875 & Standard Deviation & 5.871261 \\
\hline Sample Variance & 0.054785897 & Sample Variance & 34.47171 \\
\hline Kurtosis & -1.342735804 & Kurtosis & -0.9525 \\
\hline Skewness & 0.799584787 & Kewness & -0.57924 \\
\hline Range & 0.6 & Range & 16.51 \\
\hline Minimum & 11.69 & Minimum & 10.73 \\
\hline Maximum & 12.29 & Maximum & 27.24 \\
\hline Sum & 155.25 & Sum & 259.95 \\
\hline Count & 13 & Count & 13 \\
\hline
\end{tabular}

Figure 7. Descriptive statistics

Source: Authors' own research

The mean values for both the mortality rate and the infant mortality rate are representative, the groups being homogeneous, according to the values calculated for the homogeneity coefficient of 1.9 respectively 29.6.

Gross domestic product per inhabitant is one of the most widely used macroeconomic indicators to show the material well-being of the population. In Romania, the value of this indicator has a growing trend. The average GDP per capita at purchasing power parity is \$ 8500, but most values correspond to a small GDP. 


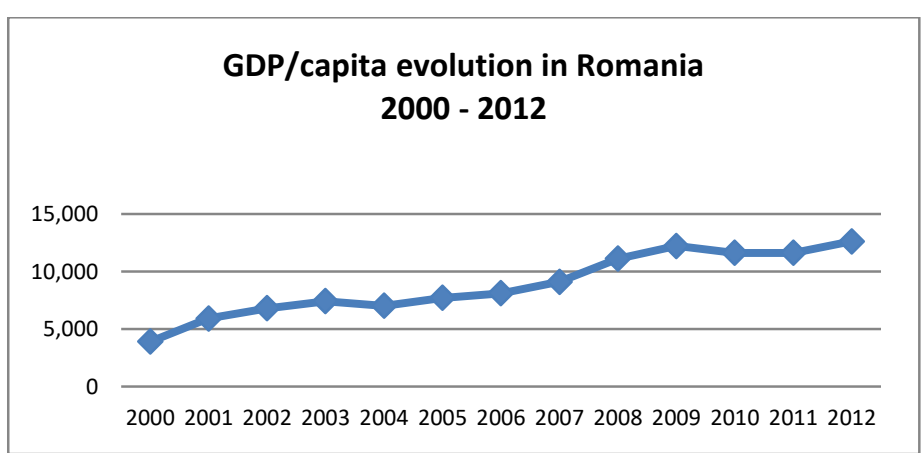

Figure 8. GDP/capita evolution in Romania between 2000-2012

Source: Romania National Institute of Statistics

Unemployment rate is the ratio between the number of unemployed and the working population. An increase in unemployment occurs when demand for jobs is higher than the supply, and is an indicator always taken into account in taking economic or social protection measures. In Romania, between 2000 and 2012, the average unemployment rate was 7\%.

The Corruption Perceptions Index is a composite index based on data on both administrative corruption and political corruption in specialized surveys based on the perceived level of corruption among officials and politicians. Corruption Perceptions Index is produced annually by Transparency International. The index has values measured on a scale between 0 (very corrupt) and 10 (very clean in terms of corruption). From the point of view of corruption, Romania and Bulgaria are the most corrupt countries in the European Union. There is a slight increase in the value of the index since 2007, which means that the population is starting to gain trust in public institutions.

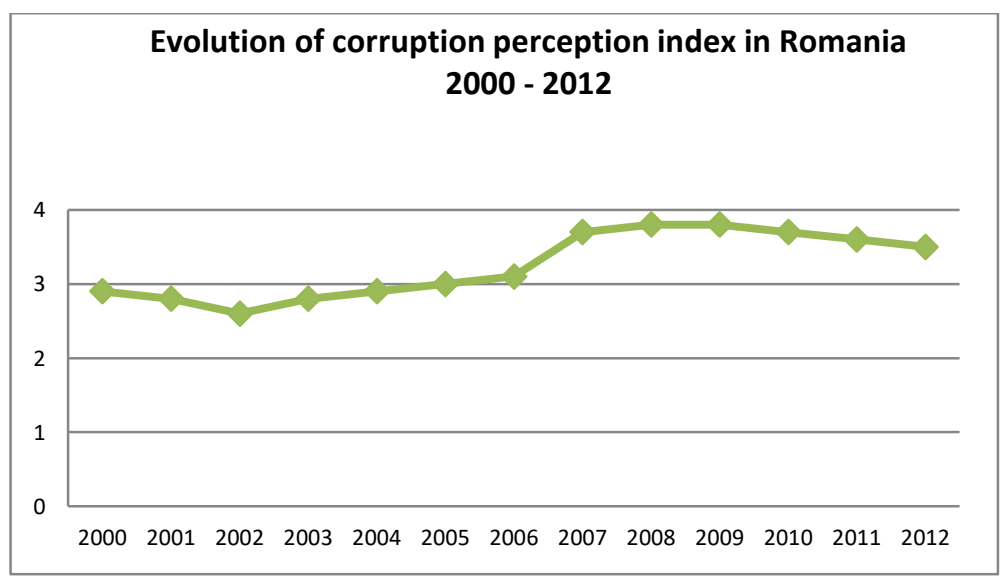

Figure 9. Evolution of corruption perception index in Romania

Source: Romania National Institute of Statistics

The last two indicators analyzed are the degree of literacy of the population, especially the population that has completed primary education and an indicator that allows us to have an overall picture of the environment, of environmental pollution. In order to have an overview of all the indicators we used, we used multidimensional statistical tools.

\section{Hierarchical classification methods - Variant method (Ward method)}

Following a procedure for a hierarchical classification method using the Ward distance 
method, which selects groups that minimize the increase in the square of errors, we obtained the following results. Using this method results two clusters.

\section{Ward Linkage}

\begin{tabular}{|l|r|r|r|r|r|r|}
\multicolumn{7}{|c|}{ Agglomeration Schedule } \\
\hline \multirow{3}{*}{ Stage } & Cluster Combined & & \multicolumn{2}{|c|}{ Stage Cluster First Appears } & \\
\cline { 2 - 5 } \cline { 5 - 6 } & Cluster 1 & Cluster 2 & Coefficients & Cluster 1 & Cluster 2 & Next Stage \\
2 & 8 & 9 & .390 & 0 & 0 & 8 \\
3 & 5 & 7 & 1.532 & 0 & 0 & 4 \\
4 & 11 & 12 & 3.349 & 0 & 0 & 10 \\
5 & 5 & 6 & 5.245 & 2 & 0 & 8 \\
6 & 2 & 4 & 7.593 & 0 & 0 & 7 \\
7 & 1 & 3 & 11.044 & 0 & 0 & 7 \\
8 & 1 & 2 & 14.942 & 6 & 5 & 11 \\
9 & 5 & 8 & 22.602 & 4 & 1 & 9 \\
10 & 5 & 10 & 32.738 & 8 & 0 & 10 \\
11 & 5 & 11 & 58.594 & 9 & 3 & 11 \\
\hline
\end{tabular}

Figure10. Variation Method (Metoda Ward)

Source: Authors' own research

In Agglomeration Schedule there is grouping classes according to distances in the proximity matrix. Each row represents one stage of the variation grouping process, numbered 1 through 9. The first grouping solution appears in the last row, while the first row represents the cluster containing all variants.

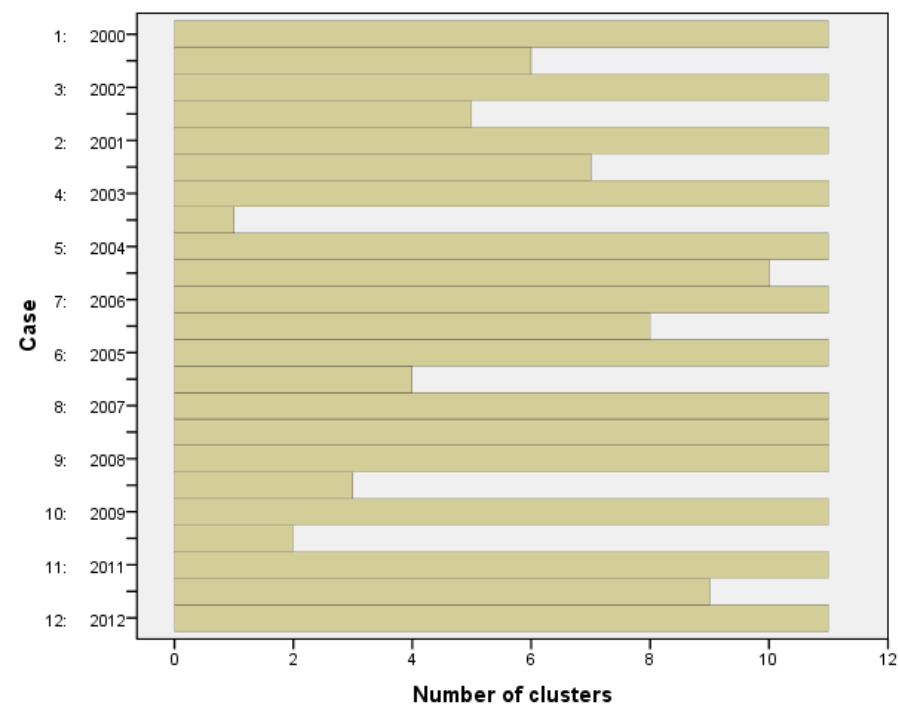

Figure11. Number of clusters determination

Source: Authors' own research

The characteristic feature of the Ward method is that by merging two clusters, it is intended to achieve maximum homogeneity in all clusters belonging to a given cluster object configuration. In this respect, it can be said that the Ward distance between two clusters 
measures the cumulative intracellular variability induced by the clustering of the two clusters at the level of the resulting cluster configuration.

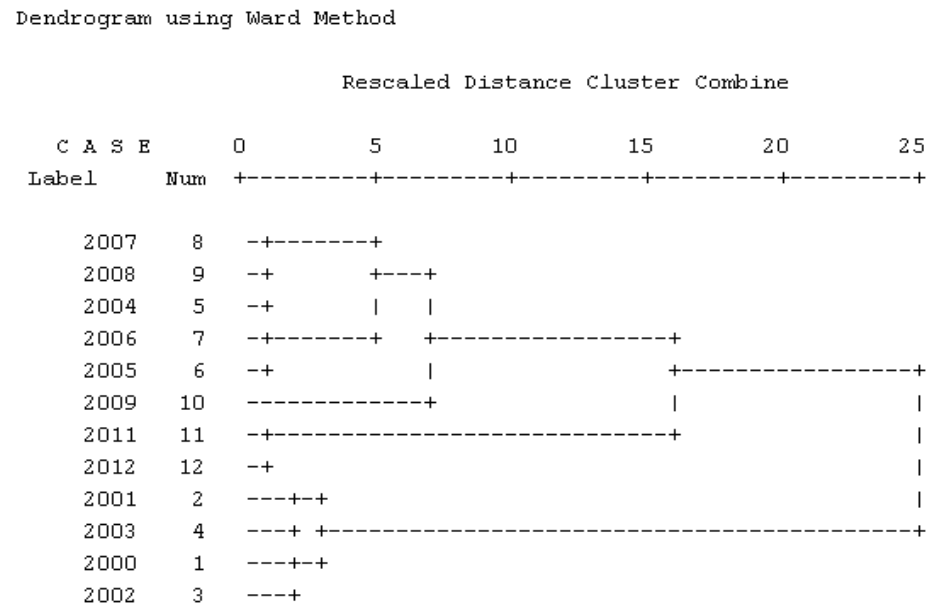

Figure 12. Dendogram and visual representation of obtained clusters

Source: Authors' own research

\section{Non-linear classification methods - K-means method}

After applying the K-means method for the whole set of variables analyzed and introducing a number of 2 clusters, we obtained the following results. The two clusters contain the information as follows: the first cluster formed between $2000-2007$ and the second 20082012.

Also, the initial ANOVA table indicates that there are some variables used in statistically insignificant analysis, which is why the analysis will be reversed by removing the insignificant variables for those for which the significance level is less than 0.05: the mortality rate, infant mortality rate, unemployment rate, and pollution indicator.

ANOVA

\begin{tabular}{|l|r|r|r|r|r|r|}
\hline & \multicolumn{2}{|c|}{ Cluster } & \multicolumn{2}{c|}{ Error } & \\
\cline { 2 - 6 } & Mean Square & \multicolumn{1}{c|}{ df } & Mean Square & \multicolumn{1}{c|}{ df } & \multicolumn{1}{c|}{ F } & \multicolumn{1}{c|}{ Siq. } \\
\hline Life expectancy & 14.183 & 1 & .704 & 10 & 20.157 & .001 \\
Natality Rate & .981 & 1 & .144 & 10 & 6.831 & .026 \\
Mortality Rate & .123 & 1 & .051 & 10 & 2.433 & .150 \\
Infantile Mortality Rate & 38.639 & 1 & 29.347 & 10 & 1.317 & .278 \\
GDP/capita (\$) & $6.264 \mathrm{E} 7$ & 1 & 1949657.143 & 10 & 32.129 & .000 \\
Unemployment Rate & 12.758 & 1 & 3.544 & 10 & 3.600 & .087 \\
Literacy Rate & 8.773 & 1 & 1.406 & 10 & 6.241 & .032 \\
Corruption perception index & 1.907 & 1 & .022 & 10 & 85.785 & .000 \\
Pollution Index & .434 & 1 & .973 & 10 & .446 & .519 \\
\hline
\end{tabular}

The $F$ tests should be used only for descriptive purposes because the clusters have been chosen to maximize the differences among cases in different clusters. The observed significance levels are not corrected for this and thus cannot be interpreted as tests of the hypothesis that the cluster means are equal.

Figure13. ANOVA table

Source: Authors' own research is:

After restoring the analysis using only statistically significant variables, the situation 
ANOVA

\begin{tabular}{|l|r|r|r|r|r|r|}
\hline & \multicolumn{2}{|c|}{ Cluster } & \multicolumn{2}{c|}{ Error } & & \\
\cline { 2 - 5 } & Mean Square & df & Mean Square & df & \multicolumn{1}{c|}{ F } & Siq. \\
\hline Life expectancy & 12.537 & 1 & .576 & 9 & 21.768 & .001 \\
Natality Rate & 1.637 & 1 & .144 & 9 & 11.353 & .008 \\
GDP/capita (\$) & $4.667 \mathrm{E} 7$ & 1 & 541814.815 & 9 & 86.135 & .000 \\
Literacy Rate & 8.869 & 1 & 1.380 & 9 & 6.429 & .032 \\
Corruption perception & 1.200 & 1 & .086 & 9 & 13.912 & .005 \\
index & & 1 & & & & \\
\hline
\end{tabular}

The $F$ tests should be used only for descriptive purposes because the clusters have been chosen to maximize the differences among cases in different clusters. The observed significance levels are not corrected for this and thus cannot be interpreted as tests of the hypothesis that the cluster means are equal.

Figure14. ANOVA table

Source: Authors' own research

The two clusters consist of 5 , respectively 6 years. Regarding the characteristics of each cluster, we note the following:

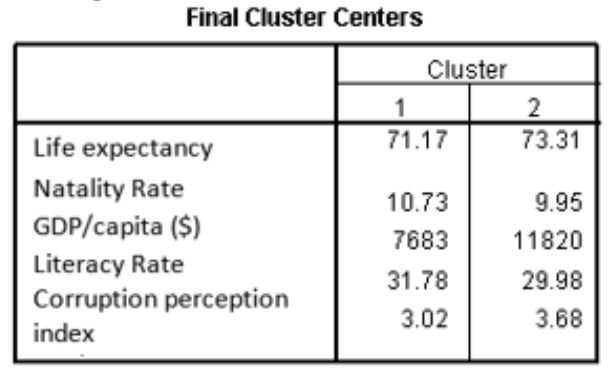

Figure15. Clusters characteristics

Source: Authors' own research

The first cluster is characterized by a lower life expectancy, a high analytical rate, a lower per capita income and a more pronounced corruption phenomenon. Comparing with the data obtained for the second cluster, where the corruption phenomenon decreases, the life expectancy and per capita income increases, we can assume that the quality of life in the first cluster is lower than in the second cluster. The first cluster contains information on the period 2000-2007 when the quality of life was weaker, with the second cluster being the information from 2008 to 2012 with a slight improvement in the quality of life.

\section{Analysis in main components}

The main component analysis is a multidimensional analysis technique that aims to reduce the dimensional dimension of the initial causal space under conditions of minimal information loss. The main components are new variables whose informational content, taken exclusively from the original variables, is defined, in relation to the links that exist between the original variables.

\section{Kaiser Criterion and Coverage Criterion}

According to these criteria, the analysis retains a number of main components that have their own supra-unit value and which take over $65 \%$ of the initial information quantity. From the output we see we have three components with the significance variance, which means we keep three main components. 


\begin{tabular}{|c|c|c|c|c|c|c|c|c|c|}
\hline \multirow[b]{2}{*}{ Component } & \multicolumn{3}{|c|}{ Initial Eigenvalues } & \multicolumn{3}{|c|}{ Extraction Sums of Squared Loadings } & \multicolumn{3}{|c|}{ Rotation Sums of Squared Loadings } \\
\hline & Total & $\%$ of Variance & Cumulative $\%$ & Total & $\%$ of Variance & Cumulative $\%$ & Total & $\%$ of Variance & Cumulative $\%$ \\
\hline 1 & 4.571 & 50.788 & 50.788 & 4.571 & 50.788 & 50.788 & 3.339 & 37.099 & 37.099 \\
\hline 2 & 2.126 & 23.622 & 74.411 & 2.126 & 23.622 & 74.411 & 2.860 & 31.783 & 68.882 \\
\hline 3 & 1.225 & 13.616 & 88.027 & 1.225 & 13.616 & 88.027 & 1.723 & 19.145 & 88.027 \\
\hline 4 & .540 & 6.004 & 94.031 & & & & & & \\
\hline 5 & .329 & 3.659 & 97.690 & & & & & & \\
\hline 6 & .197 & 2.188 & 99.878 & & & & & & \\
\hline 7 & .008 & .091 & 99.969 & & & & & & \\
\hline 8 & .003 & .031 & 100.000 & & & & & & \\
\hline 9 & $1.580 \mathrm{E}-5$ & .000 & 100.000 & & & & & & \\
\hline
\end{tabular}

Extraction Method: Principal Component Analysis.

Figure16. Total variance

Source: Authors' own research

In the Cumulative column, it is noted that the first two main components take up 88\% of the amount of initial information. Based on the three criteria, I will consider three main components in the analysis.

KMO and Bartlett's Test

\begin{tabular}{|c|c|c|}
\hline \multicolumn{2}{|c|}{ Kaiser-Meyer-Olkin Measure of Sampling Adequacy. } & .245 \\
\hline $\begin{array}{l}\text { Bartlett's Test of } \\
\text { Sphericity }\end{array}$ & $\begin{array}{l}\text { Approx. Chi-Square } \\
\text { df } \\
\text { Sig. }\end{array}$ & $\begin{array}{r}116.848 \\
36 \\
000\end{array}$ \\
\hline
\end{tabular}

Figure17. Test KMO, Bartlett

Source: Authors' own research

The Kaiser-Meyer-Olkin index (0.245) is used to compare the dimensions of the correlation coefficients observed with the dimensions of the partial correlation coefficients. The value of Bartlett's Test of Sphericity $(116,848$, Sig.000) is small enough to reject the hypothesis that the variables are uncorrelated, so there is a strong relationship between the data.

Communality is that part of the variance of a variable explained by the structure of a factor. Minimum values of the common character for certain variables indicate that these variables are not well represented by the applied factorial model. In my example, we can see that most of the variables are well represented by the factorial model used.

\begin{tabular}{|l|r|r|r|}
\hline \multirow{2}{*}{} & \multicolumn{3}{|c|}{ Component } \\
\cline { 2 - 4 } Life expectancy & \multicolumn{1}{|c|}{1} & \multicolumn{1}{c|}{2} & \multicolumn{1}{c|}{3} \\
\hline & -.963 & .190 & -.081 \\
Natality Rate & .833 & -.400 & .319 \\
Mortality Rate & .523 & .668 & -.029 \\
Infantile Mortality Rate & .514 & -.755 & .358 \\
GDP/capita (\$) & -.900 & .235 & .245 \\
Unemployment Rate & .457 & .757 & .177 \\
Literacy Rate & .801 & .190 & -.274 \\
Corruption perception index & -.848 & -.220 & .360 \\
Pollution Index & .183 & .447 & .832 \\
\hline \multicolumn{2}{|c|}{ Extraction Method. Principal Component Analysis. } \\
a. 3 components extracted.
\end{tabular}

Figure18. Principal components analysis

Source: Authors' own research 
The Component Matrix Table contains Factor Loads. Matrix elements are the correlations between the components and the initial variables. There is a very direct correlation of the first main component of the birth rate and literacy rate, and a direct but opposite link with life expectancy at birth, per capita income and corruption. The second main component is directly related to the mortality rate and the unemployment rate and backwards correlated with the infant mortality rate. The third component is directly correlated with the pollution indicator.

The more useful structure for interpretation is the one obtained after spin of the factors.

\begin{tabular}{|l|r|r|r|}
\hline \multicolumn{1}{|c|}{ Rotated Component Matrix } \\
\hline & \multicolumn{3}{|c|}{ Component } \\
\cline { 2 - 4 } & 1 & 2 & 3 \\
\hline Life expectancy & .631 & -.745 & -.130 \\
Natality Rate & -.331 & .908 & .148 \\
Mortality Rate & -.664 & -.149 & .508 \\
Infantile Mortality Rate & .066 & .972 & -.113 \\
GDP/capita (\$) & .736 & -.601 & .154 \\
Unemployment Rate & -.538 & -.163 & .705 \\
Literacy Rate & -.830 & .240 & .077 \\
Corruption perception index & .922 & -.212 & -.040 \\
Pollution Index ... - & .127 & .156 & .940 \\
\hline
\end{tabular}

Figure 19. Principal components analysis after factors rotation

Source: Authors' own research

According to the data obtained, the structure of the components for the analyzed variables is the following, taking into account only factors with a load of at least 0.7 . The first main component is the GDP / capita variables and the literacy rate, the corrupt perception index, which is why we will call this development index component. The second component contains life expectancy at birth, natality rate and infant mortality rate and I will call it an index of demographic phenomena. The third component is made up of the pollution indicator and is called the environmental index.

Thus, using the Main Component Analysis, I managed to synthesize the information from 9 variables, reaching three main components that took $88 \%$ of the initial information, the losses being minimal.

\section{Conclusions}

Industrialization has brought major demographic changes. Increased longevity can be seen in all industrialized countries. Rate of natality is steadily decreasing, but at the same time improving the quality of medical services has led to increased life expectancy. Life quality analysis first requires a clearer definition of this concept.

The concept of quality of life was launched in the 1960s by North American society. It has started from the fact that any economic growth must not be an end in itself but, first, it must be a means to create better living conditions to meet the needs of a particular community. There is often confusion between living standards and quality of life; the two concepts, although at first glance seem to be confusing, are still different due to the scope. It 
has also been established the link between household incomes and the consumer price index, how much the population spends on these agri-food products, the average annual per capita consumption, and the average daily dietary intake of calories and nutrients, all of which are presented in a succinct form through tables and graphs. In the context of consumer needs, food needs are a priority. The small incomes of a family affected by poverty determine the immediate change in food consumption. Romania is far from the developed European countries in terms of average wage on the economy. While in our country the average wage barely exceeds 200 euros, in countries like Austria or Germany, it is around 5,700 euros, in Spain 3,800 euros and in Italy 3,200 euros. The economic crisis in 2007-2009 had a beneficial effect on the quality of life in Romania. According to the data obtained before the crisis, the quality of life characterized by the initially established indicators was much weaker than after the crisis where it felt a slight improvement. Also, considering the index of health and a quality of life index in 2012, the last year of analysis Romania's position within the European Union is found in the third quadrant, which means a low quality of life and at the same time and poor population health. In this situation are all ex-communist or developing countries: Bulgaria. Slovakia, Hungary, Poland, Lithuania and Latvia.

\section{References}

European Commission (2009). GDP and beyond - Measuring progress in a changing world European Fundation for Quality of life and work conditions enhancement (2012). Quality of life in Europe: crisis impact

Zamfir, C (1984). Indicators and variation sources for quality of life. Romanian Academy

Carbuneanu, M (2010). Factorial analysis applied in development field. Journal of Constantin Brancusi University (1-2010)

Margineanu, I (2004). Quality of life in Romania. Romanian Academy: Quality of life journal $(3-4,2004)$

Plateau, C. (2011). Measuring quality of life. Implementing the Stiglitz Reports recommendations. Institut National de la Statistique et des Etudes Ėconomiques

Kerce, E (1992). Quality of life: meaning, measurement, and models. Navy Personnel Research and Development Center.

Hamuraru, M \& Turcanu. $O$ (2009). Conceptual approaches of quality of life in the context post-industrial society. Scientific Journal of Moldavia's University, 2 (22)

Sirbu, A \& Potang, A \& Tulbure T. Psychosocial approaches regarding quality of life. Scientific Journal of Moldavia's University, ISSN 1857-2103

Marginean, I. \& Precupetu I (2010). Quality of life in Romania. Romanian Institute for quality of life 